The Battle for Mental Health

By Dr. James Clark Moloney. Pp. xi+105. (New York: Philosophical Library, Inc., 1952.) 3.50 dollars.

$\mathrm{D}$ R. J. C. MOLONEY comes of a well-known medical family, and in his own right he is recognized as a psycho-analyst of eminence. This little book is readable and interesting, but intended principally for lay consumption. It is brought out in the interests of the Cornelian Corner movement throughout the United States and elsewhere, a movement for the return to Nature's methods of infant rearing by the mother as opposed to the modern separation of mother and infant for all purposes but 'ownership'.

Dr. Moloney develops on Freudian lines the complex behaviour, determined by the mother-child relationship, and amplifies his views by anthropological, clinical, scientific and experimental observations. He urges the warmest and most relaxed relationship between parents and infant as a true basis for emotional development. It must be remembered by those in Great Britain and elsewhere who may read this book that the American public is very interested in psychology; in fact, anything that is written or published on this theme is read with avidity.

Analytically minded readers will welcome the book in general; but many will consider it rather superficial in that it fails to give adequate consideration to other environmental influences acting on the child or to the constitutional factors involved. It is well brought out, and there are a good index and many references.

K. K. D.

\section{Totem Poles}

National Museum of Canada Bulletin No. 119 (Anthropological Series No. 30). Vol. 2 : Totem Poles according to Location. By Marius Barbeau. Pp. ix +435-880. (Ottawa: King's Printer, 1951.) 2.50 dollars.

THIS is the second volume of a work the first volume of which has already been reviewed in these columns (see Nature, February 16, p. 258). The greater part of Vol. 2 consists of notes on totem poles and other large carvings, arranged by the localities where they were set up; this part is based on Mr. Barbeau's own field-work, supplemented by the writings of others in areas with which he is less familiar. The remainder is called "Synthesis and Compilation" and contains a vast amount of interesting information about the history of the carvings and the techniques employed on them. This part consists very largely of extracts from previous writings, including some by Mr. Barbeau himself, and is extremely valuable in itself; but it would have been more useful still if some attempt had been made to digest it and set out the conclusions in the form of a summary. It is difficult, for example, to extract a clear idea of exactly when the various sorts of large carving developed, and this difficulty is accentuated by the lack of an index, which is only partly corrected by the table of contents. It seems that in Canada large detached totem poles were practically unknown before the nineteenth century, but tall posts attached to house fronts were certainly in existence by 1790 , and substantial carvings were seen inside houses by Cook in 1778. There is plenty of evidence of culture contacts with Russian traders for more than thirty years before that, and these may go back further; in fact, it is suggested that the north-west coastal tribes may themselves have come over from Siberia within the preceding few centuries.

We are given some tantalizing hints about the age of the characteristic curvilinear art of the north-west coast of Canada. They include a statement (p. 764) that the earlier work of the Haidas and Tlingits is found in the oldest museum collections of carved argillite and metal, mostly inspired by Chinese and European models, and a quotation (p. 821) from E. L. Keithahn that it was preceded by plain geometric motifs. Some of the art motifs of the Old Bering Sea Eskimos suggest that its origin should be sought in that direction. If the author would pursue the question of the age and origin of this art, he would put us greatly in his debt.

One rather blatant error was noticed. The photographs on p. 838 are repeated on p. 844, and in one case they are labelled Tlingit totems, and in the other Kaigani and Haida ones. They cannot both be right.

G. H. S. BushNelL

\section{Tycho Brahe, Mannen och Verket}

Efter Gassendi översatt med kommentar. Av Wilhelm Norlind. Pp. xxxi+364. (Lund: C. W. K. Gleerup, 1951.) $25 \mathrm{kr}$.

THE 350th anniversary of the death of the great Danish astronomer, Tycho Brahe (1546-1601), was commemorated by the publication of this book, which is a translation into Swedish of the well-known biography by Pierre Gassendi (1592-1655), entitled "Tychonis Brahei, Equitis Dani, Astronomorum Coryphæi Vita". The first edition of this biography, written in Latin, was published in 1654. This translation, by Dr. Wilhelm Norlind, will make Gassendi's work available to the peoples of Scandinavia.

But the volume is more than a mere translation. A very extensive commentary has been added. Biographical notes about persons mentioned in the text are given, along with much other information that greatly enhances the value and the interest of Gassendi's biography.

A biographical note on Gassendi, an introduction describing briefly the developments in astronomy up to the time of Tycho Brahe, a note on astrological ideas, a glossary for the benefit of non-astronomical readers of astronomical terms used in the book, a detailed bibliographical note, and an index are included.

The volume is an important addition to the literature about Tycho Brahe, and its usefulness would be enhanced if an English translation could be published. It is well printed and contains a number of illustrations.

H. S. J.

\section{Jacobian Elliptic Function Tables}

A Guide to Practical Computation with Flliptic Functions and Integrals together with Tables of sn $u$, en $u$, dn $u, Z(u)$. By Prof. L. M. Milne-Thomson. (Dover Series in Mathematics and Physics.) Pp. xi+123. (New York: Dover Publications, Inc., 1950.) 2.45 dollars.

LTHOUGH elliptic functions are useful in many branches of applied science, engineers and others have tended to avoid them because of the illusion that they are difficult to handle. This illusion will be dispelled by Prof. L. M. Milne-Thomson's excellent little volume. This not only gives a useful set of numerical tables, but is also a complete elementary sketch of the application of elliptic functions, starting 